
\title{
25 Research Suare \\ Effect of Safranal On The Response Of Cancer Cells To Topoisomerase I Inhibitors: Dose Sequence Matter?
}

\section{Lama Lozon}

University of Sharjah

\section{Ekram Saleh}

National Cancer Institute, Cairo University

Varsha Menon

University of Sharjah

Wafaa Ramadan

University of Sharjah

Amr Amin

UAE University

Raafat El-Awady ( $\sim$ relawady@sharjah.ac.ae )

University of Sharjah

\section{Research Article}

Keywords: Safranal, Topotecan, TDP1 and Combination sequence.

Posted Date: January 27th, 2022

DOI: https://doi.org/10.21203/rs.3.rs-1199263/v1

License: (c) (1) This work is licensed under a Creative Commons Attribution 4.0 International License. Read Full License 


\section{Abstract}

Background: Lung and colorectal cancers are among the leading causes of death from cancer worldwide. While topotecan (TPT), a topoisomerase 1 inhibitor, is a first- and second-line chemotherapeutic drug in treating lung and colon cancers, the development of drug resistance and toxicity still reserve as a major obstacle to chemotherapeutic success. Accumulating evidences are available that indicate increased efficacy and reduced toxicity of chemotherapeutic agents upon combining them with natural products. Safranal (SAF), a natural compound obtained from Crocus Sativus stigma has been shown to possess anti-cancer activity.

Objectives: The current work aimed to investigate the possible interaction of SAF with TPT when used in different sequences in colon and lung cancer cell lines.

Methods: The growth inhibitory effect of the proposed combination given in different sequences was assessed using the colony formation assay. Comet assay, cell cycle distribution, Annexin V staining as well as expression of proteins involved in DNA damage and repair were utilized to understand the mechanism underlying the effect of the combination.

Results: SAF enhanced the growth inhibitory effects of TPT particularly when it was added to the cells prior to TPT. This combination increased the double strand breaks (DSBs) induction and dysregulated the DNA repair machinery, particularly the tyrosyl- DNA phosphodiesterase1 enzyme (TDP1). Additionally, SAF+TPT combination increased the fraction of cells arrested at the G2/M checkpoint as well as enhanced the induction of apoptosis.

Conclusion: The current study highlights the status of SAF as a natural product sensitizing the lung and colon cancer cells to the cytotoxic effects of the anticancer drug TPT. In addition, it emphasizes the importance of sequence-dependant growth inhibition which can affect the overall outcome.

\section{Introduction}

Colorectal (CRC) and Lung cancers are among the most prevalent cancer subtypes,together they account for approximately 2.8 million deaths from cancer annually [1]. Chemotherapy is a principal option in the treatment of both types. However, its use is associated with various problems that limit its usefulness. First, they lack selectivity towards cancer cells, thus they can damage rapidly dividing normal cells including gastrointestinal tract epithelial cells and the bone marrow [2, 3]. Second, the development of resistance which can cause therapy failure $[4,5]$. Combination treatment with different anti-cancer agents remains the core practice to overcome drawbacks of conventional cancer therapy. It allows the use of more than one agent in a reduced dosage which enhances the efficacy and reduce the likelihood of severe adverse events [6]. Recently, a new option of cancer therapy has emerged, which involves combining traditional chemotherapy with a naturally-derived chemical that is showing an evidence of cytotoxicity to cancer cells and limited damage toward normal cells [7-9]. The sequence by which the 
combined agents are administered is as important as the choice of the agents themselves. This decision is based on understanding the pharmacodynamics and pharmacokinetics of the combined drugs $[10,11]$.

Topoisomerase I (TOPOI) inhibitors are important class of chemotherapy, which include topotecan (TPT) and irinotecan. They are used in the management of different types of cancers such as colon, lung and ovarian $[12,13]$. They exert their effect on TOPOI, which controls the topology of DNA and is usually required to relief the DNA supercoiling to allow a flowless DNA replication and transcription. TOPOI work by generating a nick in a single strand of DNA double helix, rotating one strand over the other, and then it re-ligates the nick. TOPOI inhibitors stabilize TOPOI-DNA cleavage complex (TOPcc) thus preventing DNA re-ligation, which results in a DNA single strand break (SSBs). This will activate SSBs repair response that involves a cascade of proteins among which is tyrosyl-DNA phosphodiesterase 1 (TDP1).

Human TDP1 is a member of the phospholipase D (PLD) superfamily and is described as a repair enzyme of TOPcc [14]. TDP1 repairs trapped TOPcc, caused by TOPOI inhibitors, by catalyzing the hydrolysis of 3-phosphotyrosyl bond located in that complex, to make DNA ends suitable for ligation $[15,16]$. Targeting TDP1 catches the attention of many scientists, suggesting that inhibiting TDP1 has the potential to augment the anticancer activity of TOPOI inhibitors by decreasing the repair of the stable complex caused by these drugs [17]. This was supported by the finding that TDP1 knockout mice are hypersensitive to TOPOI inhibitors [18]. It was reported that TDP1 tends to be overexpressed in non-small cell lung cancer (NSCLC) and CRC, which confers resistance to TPT and other TOPOI inhibitors $[19,20]$. The mutations in TDP1 that results in reduction of its catalytic activity sensitizes cancer cells to the cytotoxic effects of TOPOI inhibitors [18]. These evidences suggest the importance of TDP1 in predicting the response to TOPOI inhibitors, and thus highlighting the significance of developing inhibitors to block its activity.

Safranal (SAF) constitutes the volatile fraction of Crocus Sativus stigma [21]. It has been shown to exert anticonvulsant, antidepressant, antihypertensive, antioxidant and cytotoxic activities. These valuable effects illustrate its importance as a potential drug in the future [22]. In cancer, SAF shows promising cytotoxic effect that is specific to cancer cells. This tumoricidal observation was seen even at low concentrations where it shows no toxicities $[23,24]$. The mechanisms by which SAF is excreting its cytotoxicity on several cancer cell lines have been a hot area of research. In oral squamous cell carcinomas HSC-3 cells, SAF was able to reduce the invasiveness and migration of those cells by reducing the expression of mesenchymal markers and increased those of epithelial cells [25]. In hepatocellular carcinoma cells HepG2, SAF shows ability to induce ER stress, to increase the extent of DNA double-strand breaks, and to increase apoptosis [26].

Inspired from the ability of SAF to potentially interfere with the function of TDP1 [26], we explored, in the present study, the effect of a new combination involving the TOPOI inhibitor TPT and SAF against HCT116 and A549 cell lines. The sequence dependant effects of this combination and the mechanism of their cytotoxicity were also investigated. 


\section{Materials And Methods}

\section{Cell lines and culture conditions}

Two cancer cell lines (CRC: HCT116 and NSCLC: A549) were used in this study. The two cell lines were a generous gift from the Radiobiology and Experimental Radio Oncology lab, University Cancer Center, Hamburg University, Hamburg, Germany. All cell lines were maintained in RPMI (A549) or DMEM (HCT116) medium supplemented with 10\% fetal bovine serum and 1\% penicillin/streptomycin (Sigma Aldrich, St. Louis, MO, USA) and are kept in $37^{\square} \mathrm{C}$ humidified incubator and an atmosphere of $5 \% \mathrm{CO}_{2}$.

\section{Chemicals And Antibodies}

Topotecan hydrochloride (TPT) and Safranal (SAF) (Sigma Aldrich-Missouri-USA) were dissolved in Dimethyl sulfoxide (DMSO) (Sigma Aldrich-Missouri-USA), the stock solution of TPT was kept at $-20^{\circ} \mathrm{C}$. In preparation for an experiment, a serial dilution of TPT was done in media to achieve a concentration range of $0.001-1 \mu \mathrm{M}$, keeping the concentration of DMSO in all samples below $0.5 \%$. Primary monoclonal antibodies against $\mathrm{Y}-\mathrm{H} 2 \mathrm{AX}$ and TDP1 and Secondary antibodies (anti-rabbit and anti-mouse) were obtained from Cell Signalling Technology (Danvers, MA, USA). In addition, propidium iodide (PI), RNAase and crystal violet were purchased from (Sigma Aldrich-Missouri-USA).

\section{Colony Formation Assay (Cfa)}

SAF IC50 for each cell line was determined by CFA [27], cells were seeded in T25 $\mathrm{cm}^{2}$ culture flasks with RPMI or DMEM in densities ranging from 50 to 1200 cells per flask. This was decided based on the SAF concentration used and the doubling time of the cells. After $24 \mathrm{hrs}$, cells were treated with different SAF concentrations $(10-200 \mu \mathrm{M})$ and the control group was treated with DMSO in a concentration kept lower than $0.5 \%$. All treatments were incubated for the whole period of colony formation. CFA was also used to assess the effect of the combination TPT/SAF in different sequences on the proliferation of the two cell lines. The first sequence involves addition of SAF IC50/IC25 24 hrs before TPT $(0.001-1.0 \mu \mathrm{M})$ and the combination was incubated for $24 \mathrm{hrs}$. the second is where SAF IC50/IC25 is given simultaneously with TPT $(0.001-1.0 \mu \mathrm{M})$ and the combination was incubated for $48 \mathrm{hrs}$. Lastly, SAF IC50/IC25 was introduced $24 \mathrm{hrs}$ after TPT $(0.001-1.0 \mu \mathrm{M})$ and incubated for another $24 \mathrm{hrs}$. In this experiment Cells were seeded in T25 $\mathrm{cm}^{2}$ culture flasks in RPMI or DMEM supplemented medium. The seeding densities ranged from 50 to 20000 cells per flask. After $24 \mathrm{hrs}$, the cells were treated with SAF/TPT in different sequences. After 12-14 days when colonies of $\geq 50$ cells were observed, cells were fixed with $70 \%$ of ethanol for 30 min. After dryness, flasks were stained with $1 \%$ crystal violet for 5 min at room temperature (RT), and left to dry. The number of colonies at each treatment was counted using the microscope for the calculation of both platting efficiency (counted colonies/seeding number) and surviving fraction (plating efficiency of treated/ plating efficiency of control). The IC50 values were 
calculated by sigmoidal curve fitting models using Graph Pad Prism 3 software (GraphPad Software, San Diego, CA, USA). To assess the type of pharmacological interaction, the following isobologram equation was used: [28], I = d1/D1 $+\mathrm{d} 2 / D 2, I$ is the interaction index, $d 1$ and $d 2$ are the respective concentrations of SAF and TPT used in the combination required to produce $50 \%$ inhibition of cell growth. D1 and D2 are the concentration of each agent alone that are able to yield the same degree of effect (50\% inhibition of cell growth). If interaction index $(I)<1$, the combination is synergistic, whereas if $I=1$ its additive and if $I$ $>1$ the effect is antagonistic.

\section{Neutral Comet Assay}

To investigate the effect of SAF, TPT and their combination on DNA damage, neutral comet assay was performed according to manufacturer's protocol (Trevigen Inc, Gaithersburg, MD) following treatment with the most effective sequence, SAF IC25/IC50 added before TPT IC50. Cells were seeded in T25 cm² flasks at a density of 0.5-0.8 million cells, after 24 hrs they were treated with SAF IC25/IC50, and TPT was introduced $24 \mathrm{hrs}$ thereafter. The combination was kept for $24 \mathrm{hrs}$ then the cells were washed, harvested gently with a scraper, and counted to obtain $10^{5}$ cells / sample to be mixed with low melting point agarose (Trevigen Inc) at a proportion of 1:10. Cells/agarose mixture was evenly distributed on the comet slides and allowed to solidify before immersed in lysis buffer (Trevigen Inc) at $4^{\square} \mathrm{C}$ over-night. Next day slides were washed with neutral buffer (Tris-base, sodium acetate, $\mathrm{pH}$ of 9 ), followed by $30 \mathrm{~min} / 35 \mathrm{~V}$ electrophoresis at $4{ }^{\mathbb{C}} \mathrm{C}$. Slides were submerged in precipitation solution ( $7.5 \mathrm{M}$ ammonium acetate) followed by $70 \%$ ethanol for 30 min each. Dry slides were then stained with SYBER Gold (Invitrogen, CA, USA) in TE buffer for 30 min, washed, dried and covered. Images were captured at $20 x$ magnification in a confocal microscope (Olympus, Japan). The tail length and intensity of florescence signal in the tail area was measured using Image $\mathrm{J}(\mathrm{NIH}, \mathrm{USA})$ for at least 70 cells/ sample to calculate tail moment (tail length + tail area).

\section{Western Blot}

To study the expression of various protein markers, cells were seeded, treated as mentioned in the comet assay and the total cell lysate was obtained by incubation with lysis buffer (Glycerol, 20\% SDS \& $1 \mathrm{M}$ Tris, $\mathrm{pH}$ 6.8) containing protease inhibitor cocktail (Sigma-Aldrich, USA). Protein was quantified using DC ${ }^{\mathrm{TM}}$ protein assay kit (Bio-Rad, USA) and Western blot was performed as described previously by Ramadan et al., 2021 [29]. Samples containing equal amounts of protein $(15-30 \mu \mathrm{g})$ were loaded into the gels to be separated on either $8 \%$ or $12 \%$ SDS polyacrylamide gel and transblotted onto nitrocellulose membrane (Bio-Rad, USA). The membranes were blocked with 5\% non-fat dried milk prepared in 1X TBS-Tween 20 and incubated with primary monoclonal antibodies (1:1000) against $\mathrm{Y}$-H2AX and TDP1 and $\beta$-actin overnight at $4^{\circ} \mathrm{C}$, then the membranes were washed 3 times with $1 \mathrm{X}$ TBS-T. Secondary antibodies were prepared at dilution of $(1: 2000)$ and incubated with membrane at RT for 1 hour. The membranes were washed 3 times with 1X TBS-T. Chemiluminescence was detected by ECL method (Thermo Fisher 
Scientific-Massachusetts-USA) and developed by ChemiDoc ${ }^{T M}$ imaging system (Bio-Rad, USA). Quantification and analysis of the bands was done using ImageLab ${ }^{T M}$ software (Bio-Rad, USA).

\section{Cell Cycle Distribution Analysis}

Effect of SAF, TPT and their combination on cell cycle progression was elucidated using flow cytometry [30]. The cells were seeded in $T 75 \mathrm{~cm}^{2}$ culture flasks at variable densities for each time point (0.5-1.5 million cells/flask). After 24 hours, the cells were treated either DMSO, TPT IC50, SAF IC25, SAF IC50, SAF IC25+TPT IC50 or SAF IC50+TPT IC50. The combined treatment was done in 3 different sequences where SAF given before TPT, concurrent or after TPT treatment for HCT116. Whereas, for A549 only SAF before TPT was assessed. The flasks were incubated for different time intervals (12, 24 and $48 \mathrm{hrs})$. At each time interval the cells were harvested and washed with 1 X PBS, and fixed in $70 \%$ ethanol at $4^{\circ} \mathrm{C}$. The fixed cells were washed 2 times with 1X PBS, counted and resuspended in 1X PBS containing RNAase $(100 \mu \mathrm{g} / \mathrm{ml})$ and incubated for $30 \mathrm{~min}$ at $37^{\circ} \mathrm{C}$ on a shaker. Cells were stained with propidium iodide (PI) $(50 \mu \mathrm{g} / \mathrm{ml})$ and analysed using Accuri C6 flow cytometry (Becton Dickenson, USA). DNA histograms were obtained using FlowJo V.10 software (Tree Star, Inc-Oregon-USA).

\section{Apoptosis Assay}

The induction of apoptosis in HCT116 and A549 cells after treatment with DMSO, TPT IC50, SAF IC25/IC50 alone or in combination (SAF plus TPT) was assessed for the percentage of cells positive for either Annexin V, PI or both. The Cells were prepared according to the manufacturer's protocol FITC Annexin V Apoptosis Detection Kit (BD Biosciences, USA). $5 \mu$ l of FITC Annexin V and $10 \mu \mathrm{l} \mathrm{PI} \mathrm{(500} \mathrm{mg/ml)}$ were added and samples were incubated for $15 \mathrm{~min}$ in the dark at RT. Binding Buffer $(400 \mu \mathrm{l})$ was then added and cell staining was analysed using Accuri C6 flow cytometry (Becton Dickenson, USA).

\section{Statistical analysis}

All experiments were carried out in triplicate and repeated at least 3 times. Data are expressed as means \pm SEM. Statistical analysis was performed by unpaired student's $t$-test using Graph Pad Prism 3 (CA, USA) software (GraphPad Software). $p<0.05$ was considered statistically significant.

\section{Results}

\section{Effect of SAF on the survival of HCT116 and A549 cells}

The growth inhibition of HCT116 and A549 cells by SAF treatment was assessed using colony formation assay. SAF treatment caused concentration-dependent reduction in survival of both cell lines (Fig. 1, A). The IC50 of SAF was determined for each cell line using the best fitting curve method in prism software. 
Based on the calculated IC50 value, HCT116 is more sensitive to SAF with IC50, $49.3 \mu \mathrm{M}$ while A549 is more resistant with IC50 of $92.5 \mu \mathrm{M}$.

\section{Effect of SAF on the cytotoxic effect of TPT on HCT116 and A549 cells}

The effect of SAF and TPT combination treatment given in three different sequences on the survival of the HCT116 and A549 cells was evaluated using colony formation assay. Where the IC25 and IC50 of SAF equivalent to $(24.7 / 49.3 \mu \mathrm{M})$ for HCT116 and to $(46.3 / 92.5 \mu \mathrm{M})$ for A549 cells were used in combination with different concentrations $(0.0-1.0 \mu \mathrm{M})$ of TPT. This treatment scheme was applied for three different sequences: SAF $24 \mathrm{hrs}$ before TPT, SAF and TPT added simultaneously and SAF $24 \mathrm{hrs}$ after TPT. IC50 of TPT was $0.01 \mu \mathrm{M}$ for HCT116 cells and $0.05 \mu \mathrm{M}$ for A549 cells. This indicates that A549 cells are more resistant to TPT compared to HCT116 cells. The Combined treatment of SAF and TPT was able to decrease the IC50 of TPT in all treatment sequences in HCT116 cells (Fig. 1, B Table 1) while in A549, only when SAF was given before TPT there was a significant reduction in the IC50 of TPT (Fig. 1, C Table 1). It is worth mentioning that incubation of HCT116 cells with SAF 24 hrs before addition of TPT resulted in 16.8 fold increase in the sensitivity of the cells to TPT (IC50 of TPT alone is $0.01 \mu \mathrm{M}$ compared to $0.00069 \mu \mathrm{M}$ for SAF + TPT) (Fig. 1, B) (Table 1). The type of pharmacological interaction between SAF and TPT was determined using the isobologram equation. In HCT116 cells, the interaction between SAF IC25 and TPT in all treatment sequences was synergistic, while the interaction of SAF IC50 with TPT was additive when SAF was given before TPT. For A549 cells, the interaction of SAF IC25/IC50 was additive when SAF was added before TPT, while the other sequences showed antagonistic interaction (Table 2). 
Table 1

IC25/IC50 values after treatment of HCT116 and A549 cell lines with TPT and TPT+SAF at different sequences

\begin{tabular}{|lll|}
\hline & IC50 $(\mu \mathrm{M})$ & \\
\hline Cell line & HCT116 & A549 \\
\hline TPT alone & $0.0100 \pm(0.0013)$ & $0.0496 \pm(0.0067)$ \\
\hline SAF IC25+TPT & & \\
\hline Before & $0.0028 \pm(0.0004)$ & $0.0280 \pm(0.0077)$ \\
\hline Concurrent & $0.0018 \pm(0.0010)$ & $0.0226 \pm(0.0194)$ \\
\hline After & $0.0021 \pm(0.0002)$ & $0.0191 \pm(0.0033)$ \\
\hline SAF IC50+TPT & $0.0007 \pm(0.0006)$ & $0.0098 \pm(0.0184)$ \\
\hline Before & $0.0025 \pm(0.0017)$ & $0.0257 \pm(0.0103)$ \\
\hline Concurrent & $0.0012 \pm(0.0002)$ & $0.0258 \pm(0.0009)$ \\
\hline $\begin{array}{l}\text { After } \\
\text { IC25 }(\mu M): \text { the concentration of the drug necessary to produce } 25 \% \text { inhibition of cell growth. IC50 } \\
\text { ( } \mu \mathrm{M}): \text { the concentration of the drug necessary to produce } 50 \% \text { inhibition of cell growth. Represented } \\
\text { data are means } \pm \text { SEM of at least } 3 \text { independent experiments. }\end{array}$ \\
\hline
\end{tabular}


Table 2

Effect of SAF on TPT cytotoxicity in HCT116 and A549 cells and the type of interaction after each treatment and sequence

\begin{tabular}{|c|c|c|c|c|}
\hline \multicolumn{5}{|l|}{ IC50 ( $(\mu \mathrm{M})$} \\
\hline Cell line & НCT116 & & A549 & \\
\hline $\begin{array}{l}\text { SAF } \\
\text { IC25+TPT }\end{array}$ & $\begin{array}{l}\text { Interaction index } \\
(\mathrm{I})\end{array}$ & $\begin{array}{l}\text { Type of } \\
\text { interaction }\end{array}$ & $\begin{array}{l}\text { Interaction index } \\
(\mathrm{I})\end{array}$ & $\begin{array}{l}\text { Type of } \\
\text { interaction }\end{array}$ \\
\hline Before & $0.76 \pm(0.03)$ & Synergy & $1.04 \pm(0.069)$ & Additivity \\
\hline Concurrent & $0.73 \pm(0.04)$ & Synergy & $1.33 \pm(0.068)$ & Antagonistic \\
\hline After & $0.80 \pm(0.1)$ & Synergy & $1.40 \pm(0.058)$ & Antagonistic \\
\hline \multicolumn{5}{|l|}{$\begin{array}{l}\text { SAF } \\
\text { IC50+TPT }\end{array}$} \\
\hline Before & $1.00 \pm(0.038)$ & Additivity & $1.05 \pm(0.013)$ & Additivity \\
\hline Concurrent & $1.32 \pm(0.07)$ & Antagonistic & $1.95 \pm(0.085)$ & Antagonistic \\
\hline After & $1.17 \pm(0.1)$ & Antagonistic & $2.21 \pm(0.102)$ & Antagonistic \\
\hline
\end{tabular}

\section{Effect of SAF, TPT and their Combination on the induction of DNA Damage}

TPT exerts its cytotoxic effect via induction of single strand breaks (SSBs) which are converted to double strand breaks (DSBs) during DNA replication. So, we next investigated by neutral comet assay the contribution of SAF to the overall seen DNA damage upon combination given in the most effective sequence. Both HCT116 and A549 cells were treated with SAF IC25/IC50 24 hrs before addition of TPT IC50, then the combined therapy was incubated for another $24 \mathrm{hrs.} \mathrm{HCT116} \mathrm{cells} \mathrm{showed} \mathrm{a} \mathrm{significant}$ increase in the extent of DNA damage (DSBs) in the combined treatment compared to TPT $0.01 \mu \mathrm{M}$ alone with both SAF IC25/IC50 (Fig. 2, A-D). However, the effect was more pronounced with SAF IC50 combination (Fig. 2, C). In A549 cells both SAF IC25/IC50 combined with TPT $0.05 \mu$ M caused a similar increase in DSBs induced compared to TPT alone (Fig. 2, E-H). Phosphorylated H2AX histone protein ( $\mathrm{YH} 2 \mathrm{AX}$ ) normally forms nuclear foci at DNA break sites in cells experiencing DNA damage. It is therefore used as a DNA damage marker, and was used in the current study to confirm the finding from comet assay. HCT116 cells were treated with SAF IC25/IC50 given 24hrs before TPT $0.01 \mu \mathrm{M}$. There was a significant increase in the level of $\mathrm{YH} 2 \mathrm{AX}$ after the combined treatment with SAF IC50 and TPT $0.01 \mu \mathrm{M}$ (Fig. 3, A). A similar pattern of increase in YH2AX was also seen in A549 cells (Fig. 3, B).

\section{Effect of the Combined treatment SAF and TPT on the modulation of DNA repair}


TDP1 is a key enzyme required to repair SSBs induced by TPT. SAF was reported to bind to TDP1 in an inhibitory manner. Thus, we investigated the changes in the expression level of TDP1 following treatment with SAF IC25/IC50 given before TPT IC50. In both cell lines (HCT116 and A549) the combined treatment of SAF IC50 and TPT IC50 significantly reduced the expression of TDP1 (Fig. 3, A \& B). However, the combination IC25 SAF with TPT reduced the expression of TDP1 in HCT116 only (Fig. 3, A \& B).

\section{Effect of the combined treatment SAF plus TPT on the cell cycle progression}

Cell cycle distribution analysis of both cell lines at 12, 24 and 48 hrs intervals were done to determine the effect of combining SAF IC25/IC50 with TPT at the sequences that showed a significant reduction in the IC50 of TPT in the proliferative assay. Combination of SAF IC50 and TPT $0.01 \mu \mathrm{M}$ in HCT116 cells caused an increase in the fraction of cells arrested at G2/M checkpoint at 12, 24 and 48 hrs when SAF was given before TPT (Fig. 4A and S1A). The same effect was achieved at $48 \mathrm{hrs}$ only in the treatment sequence where SAF is given simultaneously with TPT (Fig. 4B and S1B). SAF IC25 was only able to increase G2/M cells when given after TPT $0.01 \mu \mathrm{M}$ at the 12 hrs interval (Fig. $4 \mathrm{C}$ and S1C). For A549 cells, treatment with SAF IC25/IC50 before $0.05 \mu \mathrm{M}$ of TPT showed statistically significant increase in the fraction of cells arrested at G2/M checkpoint at 24 hrs post treatment compared to TPT $0.05 \mu \mathrm{M}$ alone only (Fig. 4D and S1D). Other time points didn't show any change in the cell cycle distribution among single or combination treatments (Fig. 4D).

\section{Saf Enhances Induction Of Apoptosis When Combined With Tpt}

The main proposed mechanism of safranal's cytotoxicity is its ability to induce apoptosis. So, we performed annexin $V$ staining for HCT116 cells which revealed an increase in annexin+/PI+ cells at 24 and $48 \mathrm{hrs}$ with SAF IC25/IC50 combined with TPT which indicates late apoptosis (Figure 5A and S2A). The same results were observed when A549 cells were treated with SAF IC50 given before TPT at 48 hrs (Fig. 5B and S2B).

\section{Discussion}

Resistance of cancer cells and low safety profile of anti-cancer drugs are two major factors limiting the success of cancer therapy. Combining natural products with current anti-cancer drugs is one strategy to overcome this problem. Due to their high safety profile, natural products will not add to the toxicity of anti-cancer drugs, yet they might enhance their anti-cancer activity allowing the use of smaller doses and enhancing the therapeutic index of anti-cancer drugs. Topoisomerase 1 (TOP01) inhibitors such as topotecan and irinotecan are approved for management of colon, lung and ovarian cancers. Their clinical applications are limited to confined tumor subtypes due to profound neutropenia and bone marrow suppression associated with the effective dose [6]. They act by binding and stabilizing the cleavable complex formed between TOPOI and the DNA inhibiting the ability of TOPO1 to re-ligate the cleaved DNA 
strands thus converting temporary DNA breaks into permanent ones. These lesions are converted into DNA double-strand breaks during DNA replication or transcription when a progressing replication fork or a transcription machinery collapse upon collision with those stable cleavable complexes.

The repair of DNA lesions induced by TOPOI inhibitors is initiated by the action of tyrosyl DNA phosphodiesterase 1 (TDP1) enzyme which catalyzes the removal of abortive TOPO-1-DNA complexes by cleavage of the 3'-DNA-protein phosphotyrosyl bond arising from inability of TOPO1 to autocatalyze this reversal due to the use of TOPOI inhibitors. Recent data has shown that high levels/activity of TDP1 can negatively impact the success of therapy with TOPO1 inhibitors as there is a higher degree of TOPO1Damage reversal thus negating the ensuing DNA damages and cell death signal imparted in the cancer cell. TOP01 vs TDP1 ratio has recently become an important indicator/predictor of response to TOPO1 inhibitors [31]. High TOPO1 levels with low TDP1 levels/activity are an ideal scenario for enhanced use of TOP01 inhibitors as an effective anti-cancer strategy. Identifying TDP1 inhibitors to reduce the denominator in this ratio would extend the therapeutic benefit of the TOPO1 inhibitors. A recent study has revealed by an in-silico molecular docking that SAF can bind to the active site of TDP1 suggesting its ability to prevent TDP1 to correct single-strand breaks induced in the DNA. The same study showed that SAF can reduce the expression levels of TDP1 in HepG2 cells [26]. In the present study, we tested the effect of the natural product safranal on the anti-cancer activity of the TOPOI inhibitor topotecan. Moreover, the effect of combining SAF with TPT in different sequences was investigated.

In the current study incubation of the colon cancer cell line (HCT116) or the non-small cell lung cancer cell line (A549) with SAF (IC25 or IC50) $24 \mathrm{~h}$ prior to TPT increased the amount of DNA double-strand breaks compared to cells treated with TPT alone as indicated by the increased tail moment (Figure 2) and the increased $\mathrm{y}-\mathrm{H} 2 \mathrm{AX}$ formation (Figure 3). This may be attributed to additional induction of DNA DSB by SAF or due to the ability of SAF to inhibit the repair of TPT-induced DSBs or both.

Our results show that treatment of both cell lines with TPT alone increases the expression of TDP1, whereas combination of SAF+TPT (SAF IC25/IC50 followed by TPT IC50) reduced the expression of TDP1. This may explain the increased sensitivity of both cell lines to TPT when cells were treated with SAF followed by TPT. Reduced expression of TDP1 in combined treatment decreases the repair of TPTinduced DNA lesions and results in accumulation of more DNA lesions leading to enhanced cell death.

It is noteworthy that the sequence of adding SAF and TPT to the cells significantly affected the type of pharmacological interaction between the two compounds. Incubating the cells with SAF before TPT showed the best interaction (synergistic or additive), whereas other sequences (concurrent treatment or TPT followed by SAF) resulted in antagonistic interaction in most cases. Sequence- dependent type of pharmacological interaction of anti-cancer drugs with other compounds have been previously reported [32].

Inability of cancer cells to efficiently repair drugs-induced DNA damage stimulates cell cycle checkpoints. The main aim is to prevent cells entering the $S$ - and M-phases of the cell cycle with damaged DNA [32]. In the present investigation, incubation of cells with SAF specially before TPT resulted in increased fraction 
of cells arrested at G2 phase of the cell cycle compared to cells treated with TPT alone. TOPOI inhibitors are known to be most toxic to actively dividing cells and to induce lethal DNA lesions during $S$ phase of the cell cycle [33]. This explains the high fraction of cells arrested at $\mathrm{G} 2$ phase upon treatment with SAF+TPT. Inhibition of TDP1 by SAF reduces the repair of TPT-induced DNA damage and activates G2/M checkpoint to prevent cells from entering M phase with damaged DNA. Cells arrested at G2 phase are given more time to repair their DNA lesions or to be removed by different cell death pathways such as apoptosis. Combined treatment with SAF followed by TPT increased the fraction of apoptotic and necrotic cells in both cell lines indicating the stimulation of apoptosis/necrosis pathways upon combining SAF with TPT. This is in line with previous studies showing activation of apoptosis upon treatment of cells with topoisomerase inhibitors [34].

In conclusion, our results emphasise the importance of SAF as a candidate sensitizing agent of colon and lung cancer cells to the effect of topotecan. This sensitization showed to be sequence dependant with most profound effects when SAF is given before TPT. Furthermore, it gives an insight on understanding the mechanism of the potentiated growth inhibitory effects seen with combination treatment that involves DNA damage, DNA repair machinery, cell cycle and apoptosis. Patients with colon or lung cancer can greatly benefit from the results of this study by combining SAF with TOPOI inhibitors to enhance the anti-cancer effect, and to improve the safety profile of the TOPOI inhibitors.

\section{Abbreviations}

CFA, Colony formation assay; CRC, Colorectal cancer; DSB, double-strand break; I, Interaction index; IC50, half maximal inhibitory concentration; NSCLC, Non-small cell lung cancer; SAF, Safranal; TDP1, TyrosylDNA phosphodiesterase 1; TOP1, topoisomerase 1; TOP1 cc, Topoisomerase 1 DNA cleavage complex; TPT, Topotecan.

\section{Declarations}

Ethics approval and consent to participate: Not applicable

Consent for publication: Not applicable

Availability of data and materials: All data generated or analysed during this study are included in this published article (and its supplementary information files)

Competing interests: The authors declare that they have no competing interests.

Funding: This work was supported by the Research Funding Department, University of Sharjah, United Arab Emirates, Under grant number 2001110343

Authors' contributions: LL: Methodology, Data curation, Writing - original draft, Validation. ES: Writing original draft, Review and Editing. VM: Data curation, Methodology. WR: Data curation, 
Methodology. AA: Conceptualization. RE: Conceptualization, Supervision, Methodology, Data curation, Writing, Review and Editing. All authors read and approved the final manuscript.

Acknowledgements: Not applicable

\section{References}

1. Sung H, Ferlay J, Siegel RL, Laversanne M, Soerjomataram I, Jemal A, et al. Global Cancer Statistics 2020: GLOBOCAN Estimates of Incidence and Mortality Worldwide for 36 Cancers in 185 Countries. CA. Cancer J Clin. 2021;71: 209-249.

2. Falzone L, Salomone S, Libra M. Evolution of cancer pharmacological treatments at the turn of the third millennium. Front Pharmacol. 2018; 9.

3. Zugazagoitia J, Guedes C, Ponce S, Ferrer I, Molina-Pinelo S, Paz-Ares L. Current Challenges in Cancer Treatment. ClinTher. 2016; 38: 1551-1566.

4. El-Awady R, Saleh E, Hashim A, Soliman N, Dallah A, Elrasheed A, Elakraa G. The role of eukaryotic and prokaryotic $A B C$ transporter family in failure of chemotherapy. Front Pharmacol. 2017; 7: 1-15.

5. Mansoori B, Mohammadi A, Davudian S, Shirjang S, Baradaran B. The different mechanisms of cancer drug resistance: A brief review. Adv Pharm Bull. 2017; 7: 339-348.

6. Chabner BA, Longo DL. Cancer chemotherapy, immunotherapy and biotherapy: Principles and practice, sixth edition, Cancer Chemotherapy, Immunotherapy and Biotherapy: Principles and Practice. 2018; Sixth Edition.

7. Huang CY, Ju DT, Chang CF, Muralidhar Reddy P, Velmurugan BK. A review on the effects of current chemotherapy drugs and natural agents in treating non-small cell lung cancer. Biomed. 2017; 7: 12-23.

8. Huang XM, Yang, Z.J, Xie QZ, Zhang ZK, Zhang,HM, Ma JY. Natural products for treating colorectal cancer: A mechanistic review. Biomed. Pharmacother. 2019;117: 
109142.

9. Rejhová A, Opattová A, Čumová A, Slíva D, Vodička P. Natural compounds and combination therapy in colorectal cancer treatment. Eur J Med Chem. 2018;144:582-594.

10. Mancini R, Modlin J, 2011. Sequence: A Review of the Literature and Creation of a Sequencing Chart. J Hematol Oncol Pharm. 2011;1: 17-25.

11. Poggio F, Ceppi M, Lambertini M, Bruzzi P, Ugolini D, Bighin C, et al. Concurrent versus sequential adjuvant chemo-endocrine therapy in hormone-receptor positive early stage breast cancer patients: a systematic review and meta-analysis. Breast 2017;33: 104-108.

12. Bailly C. Irinotecan: 25 years of cancer treatment. Pharmacol Res. 2019;148:104398.

13. Vennepureddy A, Atallah JP, Terjanian T. Role of Topotecan in Non-Small Cell Lung Cancer: A Review of Literature. World J Oncol. 2015; 6: 429-436.

14. Interthal H, Pouliot JJ, Champoux JJ. The tyrosyl-DNA phosphodiesterase Tdp1 is a member of the phospholipase D superfamily. Proc Natl Acad Sci USA. 2001; 98: 12009.

15. Kawale AS, Povirk LF. Tyrosyl-DNA phosphodiesterases: Rescuing the genome from the risks of relaxation. Nucleic Acids Res. 2018; 46: 520-537.

16. Pommier Y, Huang S, Yin N, Gao R, Das BB, Murai J, Marchand C. Tyrosyl-DNA-phosphodiesterases (TDP1 and TDP2). DNA Repair (Amst). 2014; 19:114.

17. Dean RA, Fam HK, An J, Choi K, Shimizu Y, Jones SJM, Boerkoel CF, Interthal H, Pfeifer TA. Identification of a putative tdp1 inhibitor (CD00509) by in vitro and cellbased assays. J Biomol Screen.2014; 19; 1372-1382.

18. Miao ZH, Agama K, Sordet O, Povirk L, Kohn KW, Pommier Y. Hereditary ataxia SCAN1 cells are defective for the repair of transcription-dependent topoisomerase I cleavage complexes. DNA Repair (Amst). 2006; 5:1489-1494.

19. Gilbert DC, Chalmers AJ, El-Khamisy SF. Topoisomerase i inhibition in colorectal cancer: Biomarkers and therapeutic targets. Br J Cancer 2012;106:18-24.

20. Liu C, Zhou S, Begum S, Sidransky D, Westra WH, Brock M, Califano JA. Increased expression and activity of repair genes TDP1 and XPF in non-small cell lung cancer. Lung Cancer. 2007; 55: 303-311. 
21. Leone S, Recinella L, Chiavaroli A, Orlando G, Ferrante C, Leporini L, Brunetti L, Menghini L.

Phytotherapic use of the Crocus sativus L. (Saffron) and its potential applications: A brief overview. Phyther Res.2018; 32: 2364-2375.

22. Rezaee R, Hosseinzadeh H. Safranal: From an aromatic natural product to a rewarding pharmacological agent. Iran J Basic Med Sci. 2013;16:12-26.

23. Milajerdi A, Djafarian K, Hosseini B. The toxicity of saffron (Crocus sativus L.) and its constituents against normal and cancer cells. J. Nutr. Intermed. Metab. 2016; 3: 23-32.

24. Riahi-Zanjani B, Balali-Mood,M, Mohammadi E, Badie-Bostan H, Memar B, Karimi G. Safranal as a safe compound to mice immune system. Avicenna J phytomedicine 2015; 5: 441-9.

25. Zhang SP, Huang JN, Jin N, Wang XL, Jin CC. Safranal inhibits the migration and invasion of human oral squamous cell carcinoma cells by overcoming epithelialmesenchymal transition. Biomed. Res.2017; 28: 817-821.

26. Al-Hrout A, Chaiboonchoe A, Khraiwesh B, Murali C, Baig B, El-Awady R, Tarazi H, Alzahmi A, Nelson DR, GreishYE, Ramadan,W, Salehi-Ashtiani K, Amin A. Safranal induces DNA double-strand breakage and ER-stress-mediated cell death in hepatocellular carcinoma cells. Sci Rep. 2018; 8: 16951.

27. El-Awady RA, Saleh EM, Dahm-Daphi J. Targeting DNA double-strand break repair: Is it the right way for sensitizing cells to 5-fluorouracil? Anticancer. Drugs. 2010; 21: 277-287.

28. Berenbaum MC. What is synergy? Pharmacol Rev.1989; 41: 93 LP - 141.

29. Ramadan WS, Talaat IM, Hachim MY, Lischka A, Gemoll T, El-Awady R. The impact of CBP expression in estrogen receptor-positive breast cancer. Clin Epigenetics. 2021; 13:1-18.

30. Saleh EM, El-Awady RA, Abdel Alim MA, Abdel Wahab AHA.. Altered Expression of Proliferation-Inducing and Proliferation-Inhibiting Genes Might Contribute to Acquired Doxorubicin Resistance in Breast Cancer Cells. Cell Biochem Biophys. 2009;55(2):95105.

31. Meisenberg C, Ward SE, Schmid P, El-Khamisy SF. TDP1/TOP1 ratio as a promising indicator for the response of small cell lung cancer to topotecan. J Cancer Sci Ther. 2014; 6: 258-267.

32. El-Awady RA, Saleh EM, Ezz M, Elsayed AM. Interaction of celecoxib with different anti-cancer drugs is antagonistic in breast but not in other cancer cells. Toxicol Appl Pharmacol. 2011; 255: 271-286. 
33. Pommier Y. Topoisomerase I inhibitors: Camptothecins and beyond. Nat Rev Cancer 2006; 6: 789802.

34. El-Awady RA, Ali MM, Saleh EM, Ghaleb FM. Apoptosis is the most efficient death-pathway in tumor cells after topoisomerase II inhibition. Saudi Med J. 2008; 29: 558-564.

\section{Figures}


Fig. 1

A

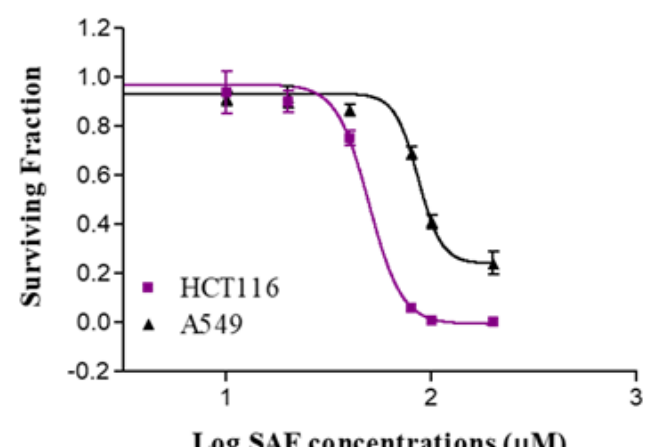

\begin{tabular}{|c|c|c|}
\hline Cell line & HCT116 & A549 \\
\hline SAF IC25 & $24.7 \mu \mathrm{M} \pm(0.021)$ & $46.2 \mu \mathrm{M} \pm(0.065)$ \\
\hline SAF IC50 & $49.3 \mu \mathrm{M} \pm(0.033)$ & $92.5 \mu \mathrm{M} \pm(0.078)$ \\
\hline
\end{tabular}

Log SAF concentrations $(\mu \mathrm{M})$
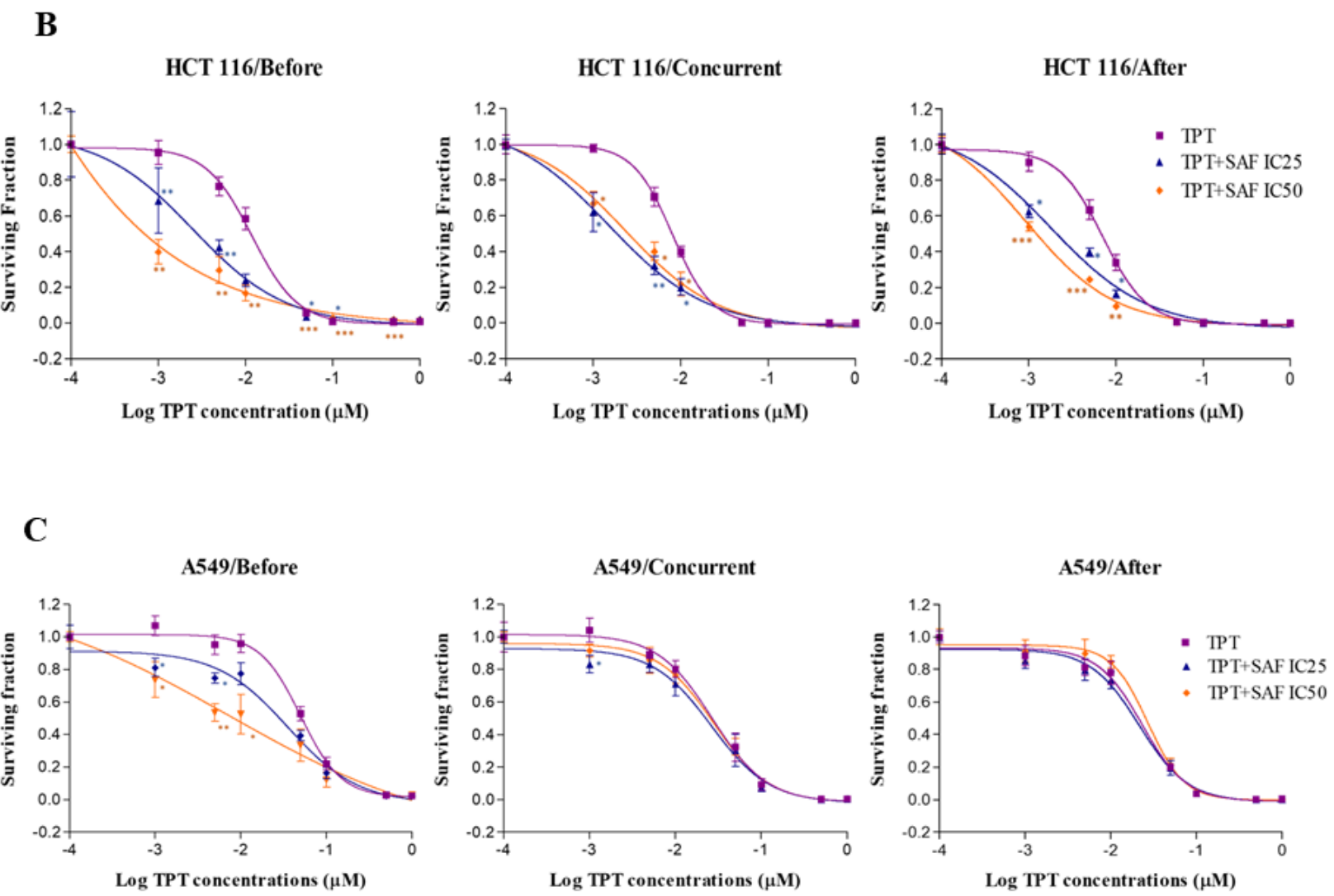

\section{Figure 1}

Effect of SAF IC25/IC50 on the sensitivity of both HCT116 and A549 cells to topotecan treatment by using different sequences

(A) Colony formation assay was used to measure the sensitivity of HCT116 and A549 cancer cell lines to different concentrations of SAF $(\mu \mathrm{M})$. (B \& C) HCT116 and A549 Cells were treated with IC25/IC50 
concentrations of SAF either $24 \mathrm{hrs}$ before, concurrently or $24 \mathrm{hrs}$ after treatment with different concentrations of TPT $(\mu \mathrm{M})$. Surviving fraction is calculated by dividing the platting efficiency (PE) of treated cells by the (PE) of control cells. Shown are the means \pm SEM of at least two independent experiments. ${ }^{*} p<0.05,{ }^{\star *} p<0.005,{ }^{\star *} p<0.0005$ vs. TPT group.

Fig. 2

A

HCT116

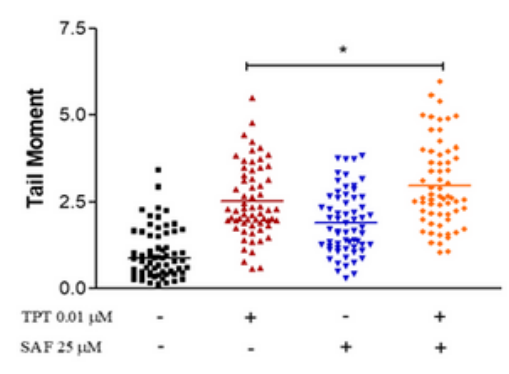

C

HCT116

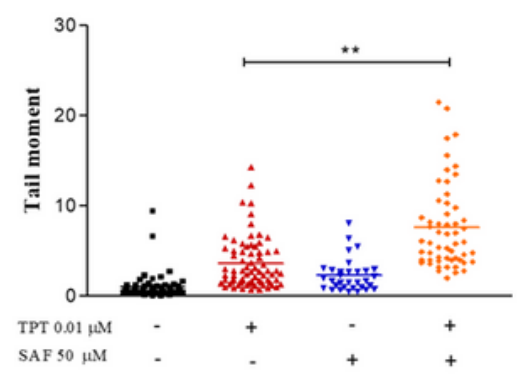

E

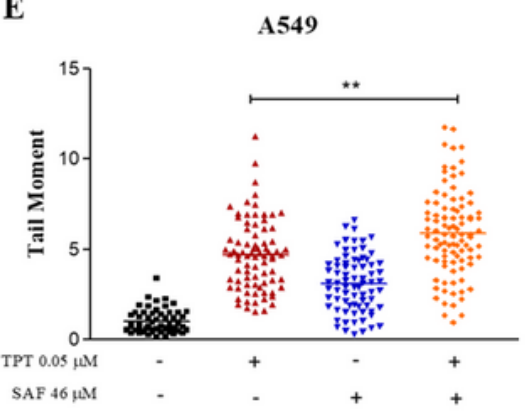

G

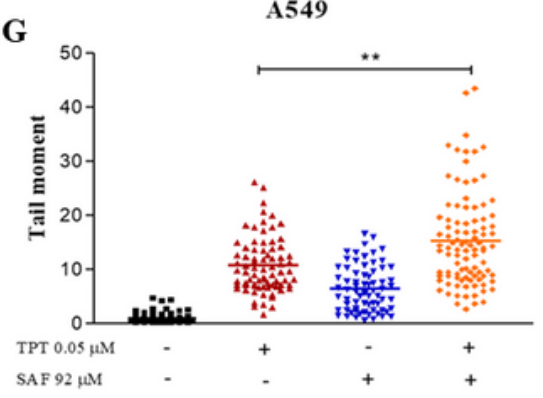

B

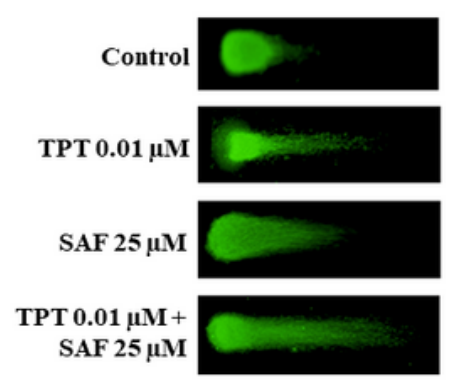

D

HCT116

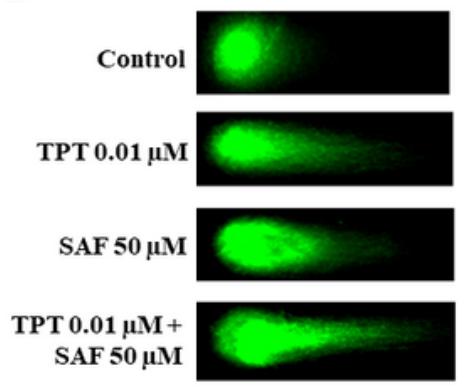

F

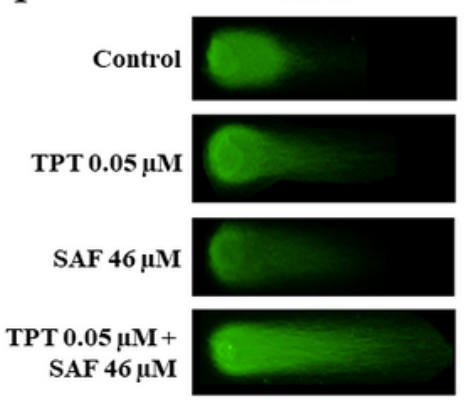

A549

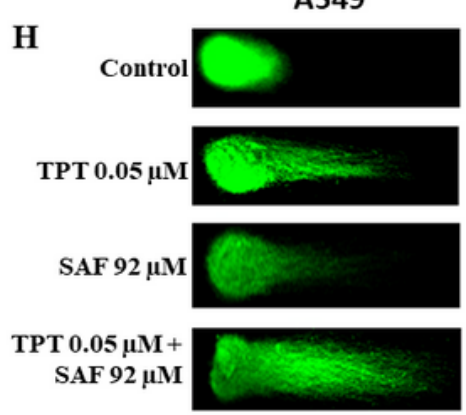


Figure 2

Neutral comet assay of HCT116 and A549 cells treated with SAF IC25/IC50 before TPT IC50 treatment for 24 hrs

(A-D) Tail moment and fluorescence microscopic images of HCT116 cells treated with SAF IC25/IC50, 24 hrs before TPT $0.01 \mu \mathrm{M}$, the combined treatment was incubated for 24 hrs. (E-H) Tail moment and florescence microscopic images of A549 cells treated with SAF IC25/IC50, 24 hrs before TPT $0.05 \mu \mathrm{M}$ and the combined treatment was incubated for $24 \mathrm{hrs}$. Shown are the means \pm SEM of at least two independent experiments. ${ }^{*} p<0.05,{ }^{*} p<0.005$ vs. TOP group. 

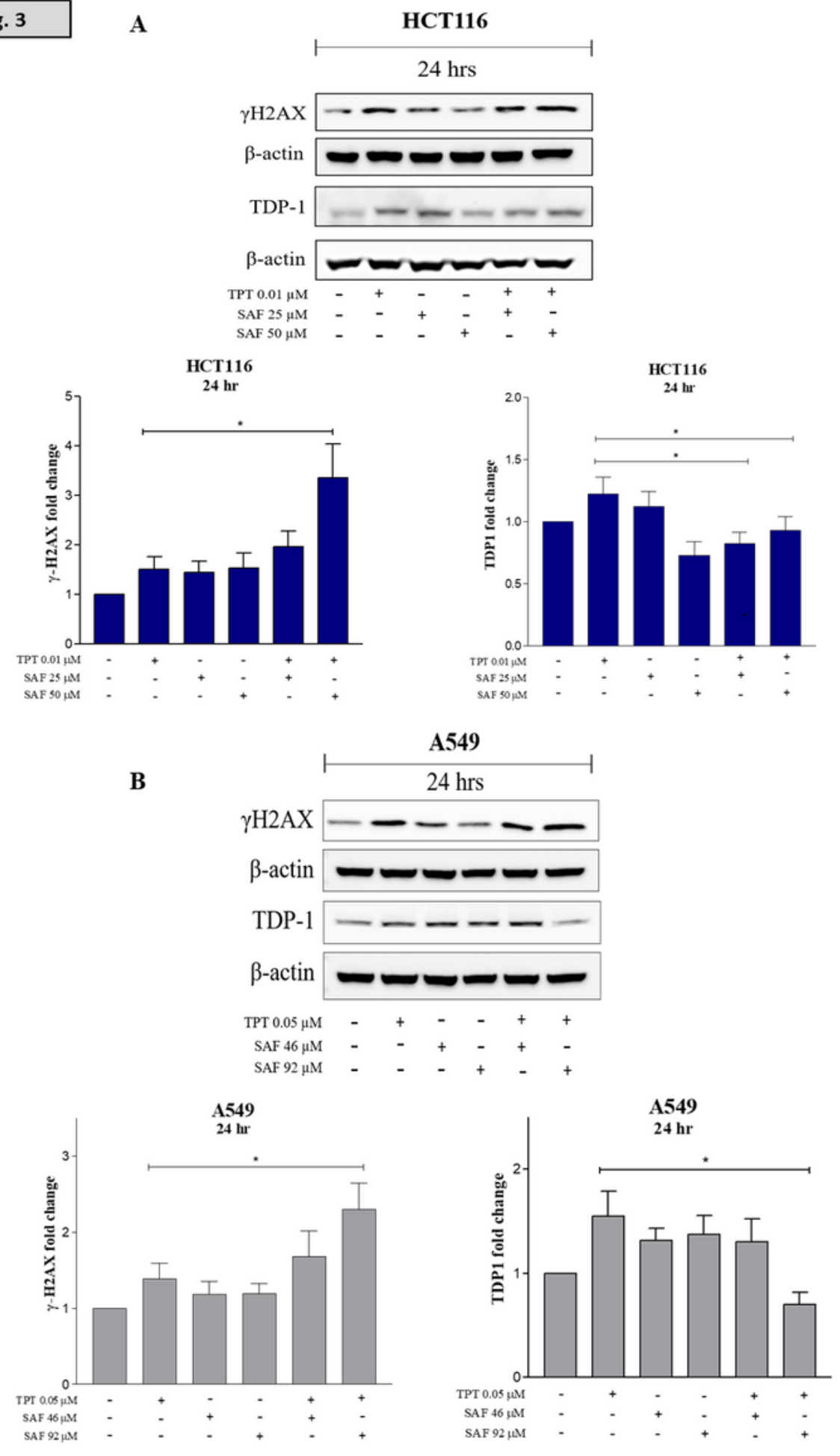

Figure 3

Expression of YH2AX and TDP1 in HCT116 and A549 cells after treatment with SAF IC25/IC50 before TPT IC50 treatment

Western blot analysis for HCT116 (A) and A549 (B) was performed by loading the whole cell lysates treated with SAF IC25/IC50 before TPT $0.01 \mu \mathrm{M}$ for 24 and 48hrs in HCT116 cells and treated with SAF 
IC25/IC50 before TPT $0.05 \mu \mathrm{M}$ for 24 and $48 \mathrm{hrs}$ in A549 cells. Bar graphs represent densitometric quantifications of western blot bands normalized to $\beta$-actin and vehicle-treated control. Shown are the means \pm SEM of at least three independent experiments. ${ }^{*} p<0.05$ vs TPT group.

Fig. 4

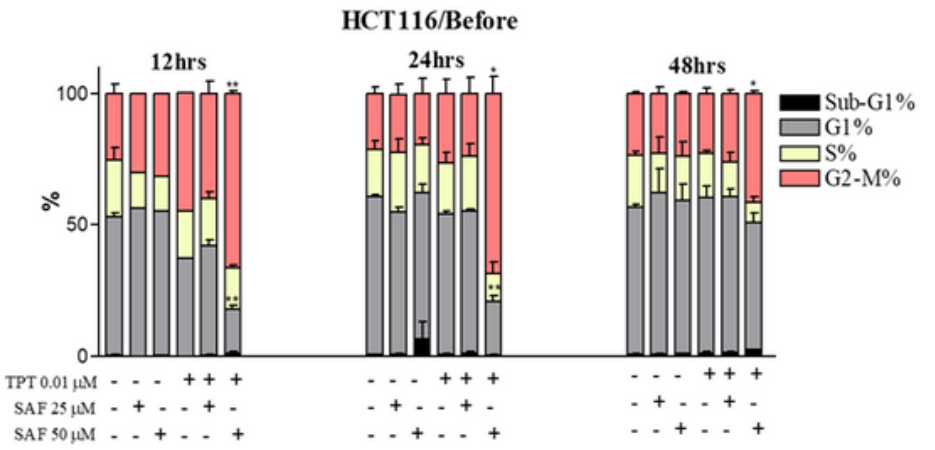

B

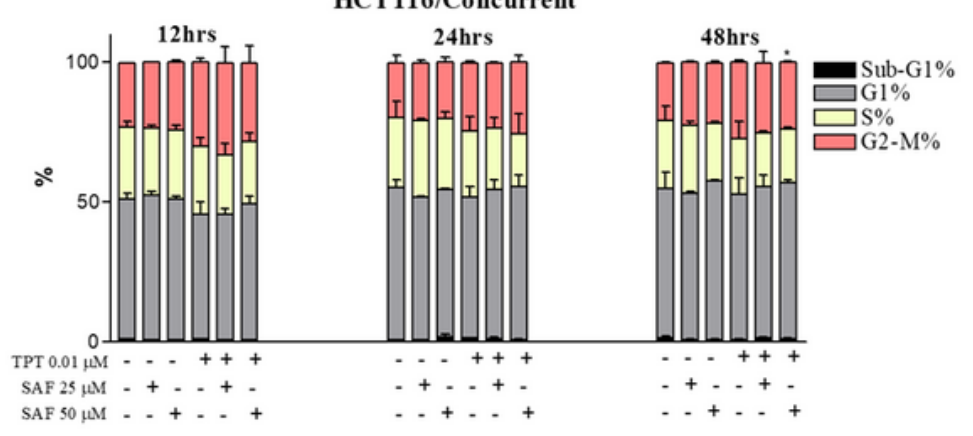

C

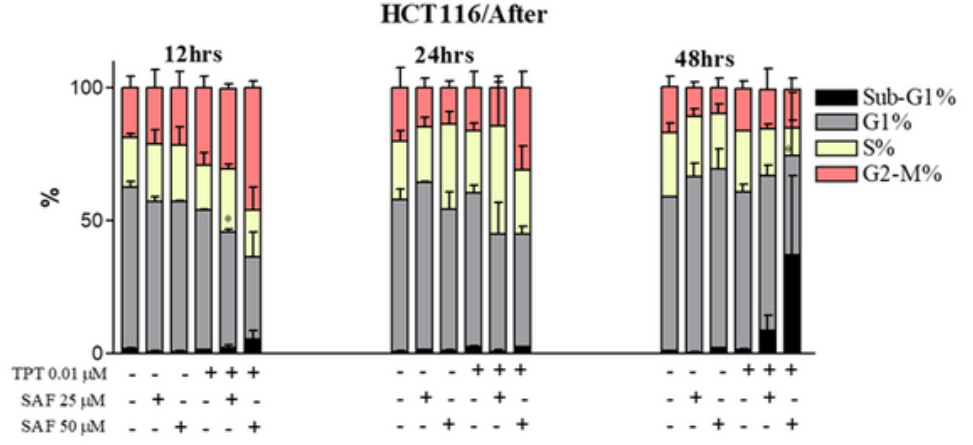

D

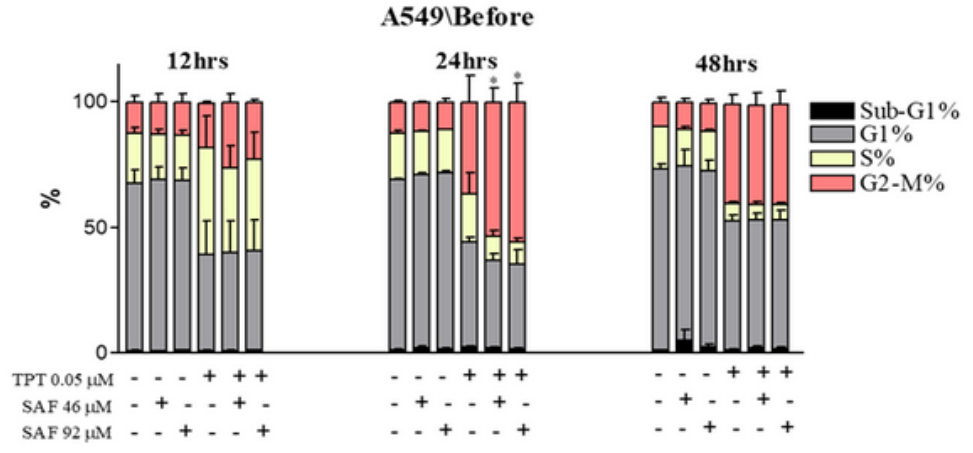

Figure 4 
Cell cycle distribution analysis of HCT116 and A549 cells treated with SAF IC25/IC50 and TPT IC50 $\mu$ M for different time intervals and sequences

(A) HCT116 cells treated with SAF IC25/IC50 24 hrs before TPT $0.01 \mu \mathrm{M}(\mathrm{A})$, concurrently with TPT 0.01 $\mu \mathrm{M}(\mathrm{B})$, and $24 \mathrm{hrs}$ after TPT $0.01 \mu \mathrm{M}(\mathrm{C})$, the combined treatment was incubated for 12, 24 and $48 \mathrm{hrs}$.

(D) A549 cells treated with SAF IC25/IC50 24 hrs before TPT $0.05 \mu \mathrm{M}$, the combined treatment was incubated for different time intervals $12,24,48 \mathrm{hrs}$. Shown are the means \pm SEM of at least two independent experiments. ${ }^{\star} p<0.05,{ }^{\star *} \mathrm{p}<0.005$ vs. TPT group. 
Fig. 5

A

HCT116

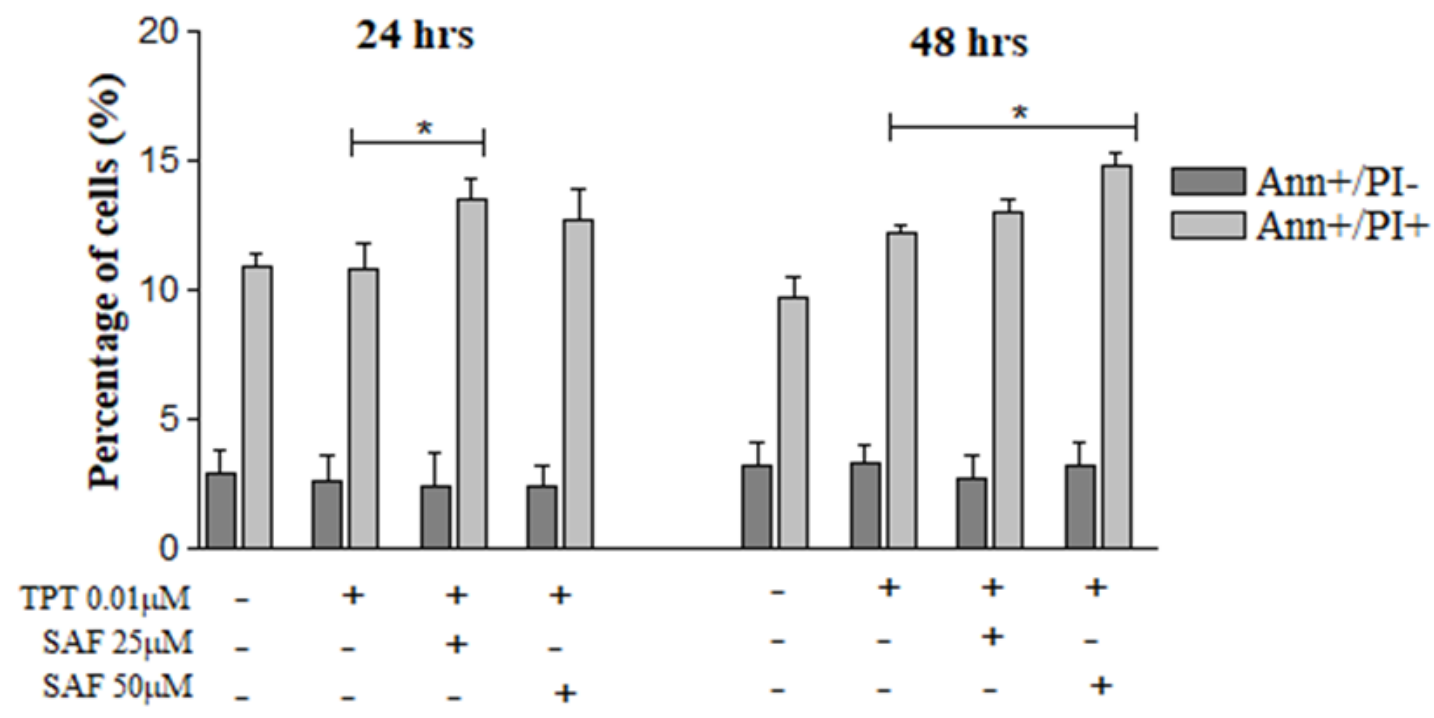

B

A549

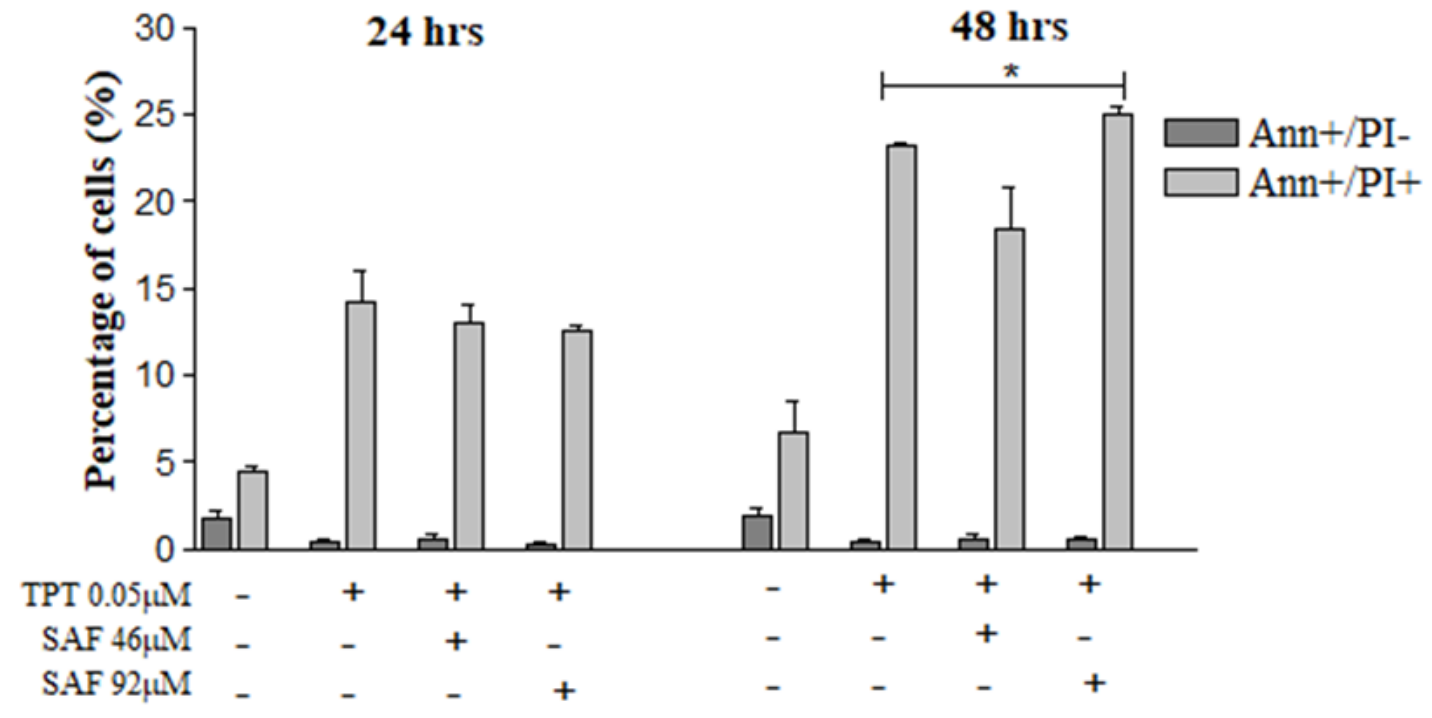

Figure 5

Annexin-V/PI flow cytometry of HCT116 and A549 cells treated with SAF IC25/IC50 before TPT IC50 treatment

Annexin-V/PI analysis of apoptosis in HCT116 cells treated with SAF IC25/IC50 24hr before TPT $0.01 \mu \mathrm{M}$ treatment. The combined treatment was incubated for $24 \& 48 \mathrm{hrs}$. Cells were stained with fluorescein- 
conjugated Annexin $\mathrm{V}$ and propidium iodide $(\mathrm{PI})$ and analysed by flowcytometry. The same analysis was done for A549 cells treated with SAF IC25/IC50 24hr before TPT $0.05 \mu \mathrm{M}$ treatment. Shown are the means \pm SEM of at least three independent experiments. ${ }^{*} p<0.05$ vs TPT group.

\section{Supplementary Files}

This is a list of supplementary files associated with this preprint. Click to download.

- Supplementmaterial.pdf 